\title{
THE IMPLICATIONS OF ADVERSE CHILDHOOD EXPERIENCES FOR THE PROFESSIONAL REQUIREMENTS OF SOCIAL WORK
}

\author{
Glynnis Dykes
}

\section{INTRODUCTION}

Coombes and Anderson (2000:281) assert that the "extent and incidence" of adverse childhood experiences (ACEs) in families of origin of social workers have increasingly become the focus of research. Their research focused on six social workers who are adult children of alcoholic families. Olson's (2006) research confirmed a high incidence of sexual and emotional abuse reported by the social work participants. This particular finding resonated with an earlier study by Black, Jeffreys and Hartley (1993), which had found that social work students report a high incidence of childhood trauma. Similarly, Earle (2008) studied early life experiences of social work students at the Universities of Limpopo and Stellenbosch. Although Schenck's (2009) research focused on the socio-economic circumstances of fourth-year social work students at the University of South Africa (Unisa) that impacted on their throughput rate, it also revealed traumatic childhood experiences. Tshiwulla (2007) found that students at the University of the Western Cape felt poor in a self-damaging way. In all three South African studies a high proportion of students reported early traumatic experiences. In addition, in Earle's (2008) study social work educators revealed their concern regarding the ethical behaviour of social work students, which appears to be affected by ACE.

\section{PROBLEM STATEMENT}

There is a dearth in the literature on research on ACEs of social work students. The few references located have linked ACE to students' choice of social work as career, their ability to make ethical decisions, and the impact on later professional acuity (Black et al., 1993; Coombes \& Anderson, 2000; Olson, 2006; Schenck, 2009). The problem in this study centres on the perception that the high incidence of ACEs endured by social work students impacts on students' learning and compromises their future professional and ethical practice. This article seeks to add to the discussion on the implications of ACE for the professional requirements of social work at South African universities.

\section{ELUCIDATION OF KEY CONCEPTS}

"Self-concept" formed the essence of the study as a focus for student expression and as a theoretical construct for the development of themes. The umbrella concept of "adverse childhood experiences" (ACE) emanates from the literature on "self-concept," as does the concept of "resilience". These terms are elucidated below in order to explain their relevance in this research.

\section{SELF-CONCEPT}

"Developing a sense of self is an essential part of every individual becoming a mature person," says Kriesberg (2003:1). How do we develop this self-concept? Bong and Skaalvik (2003) assert that our beliefs about our competencies are located in our past accomplishments and experiences, which are significant factors in our maturation. Self-concept can be viewed as our self-perception about our general competencies and skills in particular areas. Self-efficacy, on the other hand, reflects our confidence in what we can actually achieve within a specific situation (Bong \& Skaalvik, 2003; Linley, 2003). This confidence is gained through our prior 
exposure to the tasks at hand, the levels of success achieved, and positive feedback received (Bong \& Skaalvik, 2003). Our self-concept and self-efficacy will impact on our decisions, choices and courses of action (and even career choices).

\section{ADVERSE CHILDHOOD EXPERIENCE (ACE)}

The common definition of an ACE encompasses those events that occurred within the first 18 years of a person's life and include continuous physical and emotional neglect/abuse; sexual abuse; family members who use alcohol, or are involved drug abuse, who are imprisoned, depressed, mentally ill, institutionalised or suicidal; family violence; and absentee parents/caregivers (Brown, Anda, Felitti, Edwards, Malarcher, Croft \& Giles, 2010; Ness, 2009).

\section{RESILIENCE}

Resilience originates from the Latin word resilio meaning to "jump back" (Mohaupt, 2008). Salient features of resilience include factors such as: (i) being a process; (ii) possessing the capacity or ability; (iii) overcoming risk situations or adversity; and (iv) emerging relatively unscathed or having little residual risk for the future (that is a positive outcome) (Coombes \& Anderson, 2000; Luthar, Cicchetti \& Becker, 2000; Masten, Best \& Garmezy, 1990; Rutter, 1999; Saleebey, 2002). Fergus and Zimmerman (2005:299) describe promotive factors as being either "assets or resources", assets being factors within the person and resources being external to the person (see also Coombes \& Anderson, 2000; Rutter, 1999; Saleebey, 2002; Van Breda, 2001).

\section{RESEARCH METHODOLOGY}

There are three tiers to consider when undertaking a research study (Creswell, 2009). Firstly, the philosophical basis which underpins the study, where in this case the social constructivist worldview was selected. In this view participants' own views of their experiences are paramount and exploring their views must be part of the research goals (Creswell, 2009). Additionally, Creswell (2009) asserts that these viewpoints are "constructed" through interactions with others and within particular cultural and historical contexts. In the second tier, the qualitative research design was selected since it is part of social constructivist philosophy. According to Creswell (2009:4), "Qualitative research is a means for exploring and understanding the meaning individuals or groups ascribe to a social or human problem" (see also Babbie \& Mouton, 2006:270). Thirdly, in terms of methods of inquiry I have selected the phenomenological research strategy because, according to Creswell (2007), it emphasises the common experiences of participants as they describe a particular phenomenon (in this case selfconcept development).

Emerging from the strategy of inquiry, the research goal is to describe students' experiences of their self-concept development and the possible implications for the professional requirements for social work. The research question is: What is the meaning of students' experiences of their self-concept development for social work professional requirements? The sub-question is: What are the self-concept development experiences of social work students at a South African university?

\section{DATA COLLECTION}

In the South African Bachelor of Social Work first-year level at the University of the Western Cape one module taught by the researcher is Introduction to the Field of Social Work. In this 
module there are two focal areas: first, the major social challenges within the South African context; and second the different fields of practice that link with these major social challenges. The first formative task is entitled: "Who am I"? It required students to reflect on who they are by considering what had impacted on their identity and growth. This relates to the adult learning model by Kolb (1984), which has been distilled into ways of knowing, for example, through experiencing an event directly (apprehension) and ways of understanding (reflective observation) (Dykes, 2009). Each person's lived encounters with their world will inspire ("or teach") them to refine or reconstruct the narratives of their identity and self-concept (Greyling \& Brokensha, 2006:121).

This task serves as a scaffold for the other formative tasks. It is premised on the belief that students learn by moving from the familiar to the unfamiliar - that is, from what they know about their social identities and their own social challenges before considering the impact of social challenges on whole communities. This reflects the constructivist view that we "want learners to construct their narratives from the launching pad of a unique self embedded in a specific social and cultural context" (Greyling \& Brokensha, 2006:122).

The primary source of data was the students' written assignments. Two main questions were asked in the assignment: one explored the influences and experiences that shaped self-concept, and the other described how these experiences linked to the broader community. Thirty-three (33) assignments were used for the study, thus forming a non-probability, criterion sample because these participants were all familiar with the experience or phenomenon in accordance with a phenomenological study (Creswell, 2007).

\section{DATA ANALYSIS}

The assignments were scrutinised in content analysis and themes were induced, according to Creswell (2007). During data analysis the researcher had to be particularly conscious not to contaminate the data with her own preconceived beliefs and opinions arising from her familiarity and empathy with student experiences (Creswell, 2007; Groenewald, 2004). Repeated readings and working with the data allowed the participants' views to dominate. This process of "bracketing", as described by the above authors, differentiated between researcher beliefs and expectations and emerging patterns and themes in the data.

\section{DISCUSSION OF FINDINGS}

The participants reported several factors that impacted on their lives in their formative years. In terms of data analysis in the phenomenological approach, the textual description of their experiences produced three major themes related to internal events, namely, (1) self-concept development experiences; (2) The impact of self-concept development experiences on participants; and (3) positive outcomes. In terms of structural descriptions as external events (the setting and context in which the phenomenon occurred) (Creswell, 2007), a fourth theme is discussed, i.e. (4) challenging social environments.

\section{SELF-CONCEPT DEVELOPMENT EXPERIENCES}

Two sub-themes were identified in the accounts of early life experiences.

Troubled family life and relationships

Participants told of the state of their family life and troubled relationships. Family conflict was common and was characterised by violence, substance abuse, financial difficulties; being suicidal; and poor care-giving. Family relationships were not experienced as the receptacle of 
positive love, nurturance and support by most of the participants. Troubled family relationships signify that family members are no longer able to meet each other's needs, as they become no longer able to communicate meaningfully with each other (Bezuidenhout, 2004). Jekielek (1998) asserts that both marital conflict and marital disruption impact on the emotional adjustment of children, who then later develop anxiety, depression and social withdrawal. She also found that when children remain in high-conflict marital situations, they display lower levels of wellbeing than children whose parents divorce or separate following high conflict. Ayoub, Deutsch and Maraganore (1999) confirm that, though children in high-conflict divorce fare poorer than children in intact families, poor child wellbeing is linked with family conflict in both intact and divorced families.

My parents have marriage problems. My father is seldom home and my mother is faced with all the home responsibilities. Not long ago my mother tried to commit suicide and was hospitalised. Therefore I may say that my family is not stable emotionally, there is not much of happiness in our home. The one thing that will drag me down is the situation at home, it is affecting me emotionally.

Participants cited financial difficulties as a single cause more than other adverse factors. They reported on the stigma of being poor in the neighbourhood and how being poor made them feel. Duncan, Yeung, Brooks-Gunn and Smith (1998) state that childhood income poverty directly affects the happiness and success of children. This finding is based on an earlier study by Brooks-Gunn and Duncan (1997), which showed that family income related more to children's competencies than to their emotional intelligence, which then set the foundations for future success.

Sometimes when there is sport I used to sell some chips and sweets. I was missing my teenage years. I never had anyone to talk to; even now I don't disclose things because they still hurt when I am thinking about them.

As the first born I have to take care of my sibling while my mother was away looking for job in other towns. She found a job in a place called Harding. She was getting little money there. Back home, there was no one to take care of us. I was 17 years old ... and lost my concentration at school because when I am in class I used to think of how I left my home there was no food, what we were going to eat ...

My brother started to drink and use dagga because he could not cope with the things of going to school without food and coming back with no hope of getting one.

The death of one or both parents in itself is a traumatic event, but the impact on the surviving family members is severe. In their longitudinal study of predictors of adjustment after the death of a parent, Rotheram-Borus, Stein and Lin (2001) report that with the death of only one parent, young children are likely to suffer depression, anxiety and self-esteem concerns which can lead to academic difficulties, behavioural problems and suicide attempts (see also Marks, Heyjung \& Jleun, 2007).

My parents passed away in the same year but different months and left us with relatives (uncle) - that was how we get abused physically, emotionally and verbally everyday and that resulted in the lack of self confidence, self-esteem and self-image in my life.

Child abuse

The most extreme form of trauma reported by the participants was child abuse consisting of sexual and physical abuse. The participants reflected the intense trauma that brought on silence and secrecy, which in turn created further trauma. Higgins and McCabe (2003) undertook three 
studies to investigate the adjustment problems related to sexual, physical, psychological abuses, neglect, and witnessing family violence during childhood. Their findings suggest that abuse tended not be limited to one type of abuse and that psychological abuse would be prevalent in many of the types. Burton, Foy, Bwanausi and Moore (1994) and Bezuidenhout and Spies (2006) report that child sexual abuse correlates with an increasing risk of complaints associated with post-traumatic stress syndrome. Threats surrounding silence and secrecy add to the stress and anxiety levels. Children may experience aspects of depersonalisation and older children in particular may view themselves as "sexual objects". Survivors typically experience difficulty in forging interpersonal relationships and manifest self-hatred (Bezuidenhout \& Spies, 2006).

There is the day I was raped by an old man. He promised to buy me a half of bread. As a young girl I agreed. I started to cry when it was hurting. I kept that secret since from when I was young up until the present.

I can't remember being allowed to speak about my feelings, especially that which would bring shame to the family; thus resulting in my silence to the fact that I was being sexually abused for eight years. It would be hard to explain how two highly regarded people in our family would be guilty of this offence.

\section{THE IMPACT OF SELF-CONCEPT DEVELOPMENT EXPERIENCES ON PARTICIPANTS}

Two sub-themes were discerned where participants explored the impact that they thought their self-concept development experiences had on them.

Anger and self-loathing

A major task in adolescence is identity development and this may be more complicated for some than for others (Brandon, Schofield \& Trinder, 1998; Herbert \& Harper-Dorton, 2002). The participants' self-discovery has been compounded by other factors in their lives. Anger and self-loathing reported by participants precipitated their troubled behaviour. According to Herbert and Harper-Dorton (2002:99) the emotions of some teens swing from positive self to "self-hatred and self-deprecation". The participants traced their anger and self-loathing to feelings of being unloved and rejected (within the family) as well as the impact of labelling and racism (outside of the family). Feelings of extreme hopelessness manifested in three participants attempting suicide; two of them made multiple attempts. Wilburn and Smith (2005) investigated the relationship between stress, self-esteem and suicide ideation in late adolescence in a group of university students in the USA. They concluded that low self-esteem and adverse life experiences were significant factors in suicide ideation (see also Fergusson $\&$ Lynskey, 1995). A teen who is troubled and perceived to be rejected or unloved by his/her family and peer group, like these participants, may be vulnerable to the influences of a negative group as an outlet for emotions. The urge and need to fit in is especially strong and irresistible to teens (Focus Adolescent Services, 2008). Using substances makes teens feel good, relieves their stress and anxiety, and most of all they feel they are fitting in (Dykes, 2010). In this cohort substance abuse did not feature significantly. Three participants reported substance use. One in particular expounded on the impact of his drug habit on his life and the difficulties he endured to feed and the kick his drug dependence.

The boys in the class used to make fun of my skin colour and call me all sorts of names like "blacky" and "black spider"... I became a miserable and angry teenager.

I very, very nearly lost my life a few times because of wanting to commit suicide. I had nothing! I reached rock bottom. 
I started using drugs at the age of 15. It started with a cigarette, which progressed to dagga. From there it moved to taking ecstasy and speed, then acid, until my habit reached its peak and I started to use heroin.

Teen parenthood

Teen parenthood was another consequence of the troubled family experiences of the participants. They reflected the consequences of early parenthood on their lives, for example, dropping out of school and the regret of adding to the troubles of the family. Depending on how the unplanned pregnancy is dealt with, the teen parents may find it difficult to fulfil previous goals that they may have harboured for their future (Bissell, 2000).

As a teenage girl I was also affected by teenage pregnancy; at the age of 16 years I was pregnant after everything my mother has been through...I had to drop out of school and look after my baby.

When I returned from the bush I impregnated one of my girlfriends and that was a disappointment to my grandmother. My girlfriend had a miscarriage and that was more disturbing.

\section{POSITIVE OUTCOMES}

Three sub-themes explored the strengths that participants displayed while enduring adverse experiences.

Positive attitude and skills

Participants told of the positive attitude and skills they learned through enduring challenging circumstances by: (1) volunteering; and (2) playing sport. Linley (2003:602) asserts that a positive outcome to trauma jumpstarts an individual's capacity for a "higher level of functioning" than they had before. This author links a positive attitude to positive outcomes. Furthermore, a positive attitude, optimism or hope influences self-efficacy, which in turn, lays the groundwork for benefiting from adversity. In this research the high response rate to volunteering is a reflection of wanting to contribute towards the fulfilment of others (see also the sub-theme on spiritual beliefs). Participation in sport involves self-discipline and cooperation within a team to achieve a goal which reflects the common good.

In their study Masten et al. (1990) concluded that one of the characteristics of children who have recovered positively from trauma is that they have areas of competence and efficacy valued by themselves and others. The participants in this research valued the outcomes of volunteering and sport, as did those involved in these activities.

I am involved in a project in my community... we do awareness about HIV/AIDS and related diseases.

In my community I'm a member of SANCO and we discuss community problems. I'm also participating in community choir and youth meetings.

Because I play sport I was looked on as role model in my community and I always tried to reflect my passion and hard work to others.

Family support

Participants identified family support as paramount (Hepworth, Rooney \& Larsen, 2002:296). Using autobiographical essays as this research does, Smokowski, Reynolds and Bezruezko (1999) investigated the development of resilience in 88 high school students in Chicago, USA. Two factors are distilled from their study: the importance of perseverance and an awareness to 
learn from adverse events; and the motivational support from family and teachers. In their examination of data from a longitudinal study of high-risk children and families, Egeland, Carlson and Sroufe (1993) found that positive, nurturing care giving mitigated the effects of adverse experiences. At the University of the Western Cape, Tshiwulla (2007) found that rolemodelling on one person who supported the student led to hope and self-belief.

The important element in my life is my family because they are always there for me no matter what goes wrong or how tough life appears to be, we always stick together as a family and face life challenges together.

My family is very close and supportive. That makes me feel blessed because not many teenagers / young adults have this kind of support systems in their lives. People who can encourage and give them the necessary financial and emotional support.

Spiritual beliefs

Participants described the importance of religious faith in giving them a sense of support and promoting a good self-image. The spiritual dimension in their lives was further expressed through their orientation to do good work, participation in activities of interest, and orientation to help people other than themselves. These factors all impact on adolescent thriving, which, according to Dowling, Gestsdottir, Anderson, Von Eye, Almerigi and Lerner (2004), is based on parental rules, presence of a moral compass, orientation to a hopeful future, search for a positive identity and personal values.

I then started attending Sunday School, it was a time in my life where I really need God in my life. I learned so much from all the Bible studies... It taught me how to start accepting myself again. I gained self-recognition whereby I recognised or saw who I was in a positive image.

I was so strong and patient because I knew that God was on my side.

\section{CHALLENGING SOCIAL ENVIRONMENT}

Participants described the challenges such as crime, diversity of traditions and beliefs, povertystricken communities and cultures of dependency that they encountered in their daily lives. They also were concerned about the personal danger of their circumstances. This theme reflected the social challenges within the communities of the participants and identified various social issues in terms of the structural descriptions of the phenomenological research strategy. The environment presented by the participants exposes them to social stress factors that may lead to the following challenges, for example, substance usage, youth offences, school dropout, teen parenthood and early violent death (Kirst-Ashman \& Hull, 2002; Myers \& Taylor, 1998). These authors assert that children who live in extreme poverty over many years are the most vulnerable to troubled behaviour.

A lot of them are depending on the social grants, provided by the government. Because of the joblessness, the crime rate is very high, rape, drug and alcohol abuse, teenage pregnancy. Although there are positive things in the community for people to do ... people prefer sex, drugs, alcohol for leisure.

Many people are dying because of HIV/AIDS. The community believes in traditional healers ... that a male with HIV have to sleep with a virgin and will be cured. This makes HIV spread ... This increase the high rate of rape because the man with HIV attack the young female. 


\section{CONCLUSION}

The common definition of ACE views social issues with a micro lens and does not cover poverty-related and structural or environmental stressors (Brown et al., 2010; Ness, 2009). The sub-question in this research focused on the self-development experiences of social work students in a South African university. The self-concept development experiences of the social work student participants reflected family circumstances of marital conflict and financial difficulties, and also rape and child sexual, physical and psychological abuse. These traumatic experiences mirror the key elements in the definition of ACE by Brown et al. (2010) and Ness (2009). This cohort therefore did not differ from those of other studies that showed a high reporting of ACEs amongst social work students. However, this same definition did not expound on the role of a challenging social environment, in particular the impact and social stigma of being poor and going without, experienced by the participants. In a study on ACEs and mental health in young adults in the USA, Schilling, Aseltine (Jr) and Gore (2007) concluded that a high number of youths from under-resourced and disadvantaged communities enter adulthood having endured traumatic events. Their study also highlighted race as a significant factor for exposure to certain of the ACE categories, which is important in a South African context, because for the most part self-development has occurred within a particular set of socio-political experiences.

The central question in this research asked: What is the meaning of students' experiences of their self-concept development for social work professional requirements? In terms of the common features of resilience, the majority of participants demonstrated overcoming certain experiences, with positive outcomes. In their documented autobiographies they indicated their capacities and abilities by a sense of personal strength (increased self-esteem and self-worth), a willingness to help others, sharing activities, gaining skills, and community participation and involvement. They appeared hopeful, with a vision to help others, and regarded their choice of social work as a career as being a consequence of their background. Therefore, it would appear that some emerged relatively unscathed by ACE. However, for others, who can be identified by the absence of resilience as documented in their autobiographies, there may be residual emotions from their childhood experiences.

In terms of promotive factors of resilience, many responses related to intra-personal and family factors. Significant intra-personal factors appear to be participants' personal attributes, for example, a positive attitude and personality, high self-esteem and a belief in their skills and competencies. Participants cited their families as vitally important in forging their resilience through their support and belief in their capabilities and a hopeful future. In the socially deprived neighbourhoods in which they lived, participants could access resources for which $t$ hey could volunteer, which provided opportunities for the development of self-concept and self-efficacy. Participants reframed certain damaging experiences positively because they learnt coping skills, responsibilities and maturity. Some of their decision making and choices showed reasoning based on their religious beliefs. A strong religious base formed the motivation to contribute to their world, which is connected to personal thriving (Dowling et al., 2004; Linley, 2003). Resilience and religious beliefs appear to be significant factors in mitigating the risks of living in a poor social environment; this is also a conclusion of Myers and Taylor (1998).

Many participants' reactions to ACEs could be linked to moral reasoning, which relates to resilience. Their burgeoning values emanate from their belief in family and religion and their decision to overcome what was harmful in their backgrounds. The assignment of writing their autobiographies gave students the opportunity to reflect on their experiences in a structured 
way as well as to make sense of what had occurred before, and then to consider their futures in relation to these experiences.

These burgeoning values and moral reasoning could be used as a basis for learning to be ethical social workers in terms of scaffolding. The concern, though, is on those participants who may not have prevailed and who may be harbouring deep emotional scars. These participants will need to be helped to guard against using a future therapeutic relationship for catharsis. Coombes and Anderson (2000) argue that a background that consists of ACE can contribute positively to later practice competence, although they do concede that there is a chance of a negative impact on clients when social workers enter the profession in order to make sense of their own prior traumatic experiences (counter-transference). Lafrance, Gray and Herbert (2004) found that students needed to demonstrate, amongst other things, a resolution of personal life experiences and a lack of narcissism (denoted as viewing client's problems and their professional role from a self-centred perspective) in order to practice professionally.

Learning professional behaviour can be facilitated by an appropriate and modern curriculum design. For example, this assignment gave students the opportunity to reflect on their experiences in a structured way and to consider their future in relation to these experiences. Here Linley (2003:607) asserts that the narrative "facilitates recovery ... through the integration of fragmented memories", thereby "giving voice to that which was often nameless". Although valuable, this was a secondary objective; the first was the academic rationale. This initial exploratory study has given us insight into the potential of these participants and highlighted the need to know the prior learning experiences of our students. This need is captured by the social constructivist view of learning. In this approach knowledge is made as a result of the myriad social experiences we have (Bellefeuille, Martin \& Buck, 2005; Blunt, 2008; Collins \& Van Breda, 2010; Van Harmelen, 1999). Ramsden (1992) had advocated that the prior learning experiences of our students were an important starting point, because they provided insight into their font of knowledge and their potential.

The ultimate outcome of the social work degree would be professionally competent social work practitioners. One variable in this is to consider the teaching and learning of ethical reasoning. Ethically sound practice is important for our service users and the reputation of the social work profession, so our focus should be on producing students who are able to conduct themselves ethically and competently. That though is most pertinent at the tail end of the process. Selection of suitable candidates is the beginning of the process. Coombes and Anderson (2000) argue that personal qualities should be assessed when selecting future social workers, because the presence of intra-personal factors (such as resilience) would enable social workers to overcome their own ACEs impacting on overall professional competency. Ryan, McCormack and Cleak (2006) also argue for social work programmes to focus on personal qualities such as as gate keeping rather than solely on academic access criteria. Gibbons, Bore, Munro and Powis (2007) contend that social work's roots in social justice, free choice and the belief in the potential of people to change mean that it will be difficult to exclude people based on their emotional unreadiness or unsuitability. They acknowledge that the focus on personal qualities is controversial in higher education and has been long avoided by the social work profession.

In terms of the findings of this research, content analysis of autobiographies to identify ACE and resilience could be a helpful tool for: the selection of new students; the identification of existing students with low resilience; the purposeful inclusion of the findings of the autobiographies as scaffolding for helping activities; and finally, learning and practising professional behaviour. 
The limitations to this study are that the research cohort is small and confined to one research site. The process of the participants enduring their experiences and prevailing can only be inferred, as this was not explicitly included in the structure of the assignment. Longitudinal research is required to explore the outcome of this cohort of students in terms of their selfconcepts and professional behaviour.

\section{BIBLIOGRAPHY}

AYOUB, C., DEUTSCH, R. \& MARAGANORE, A. 1999. Emotional distress in children of high-conflict divorce: the impact of marital conflict and violence. Family and Conciliation Courts Review, 37(3):297-314.

BABBIE, E. \& MOUTON, J. 2006. The practice of social research (SA ed). Cape Town: Oxford University Press.

BELLEFEUILlE, G., MARTIN, R. \& BUCK, M. 2005. From pedagogy to technagogy in social work education: a constructivist approach to instructional design in an online, competency-based child welfare practice course. Child \& Youth Care Forum, 34(5):371-389.

BEZUIDENHOUT, F. 2004. A reader on selected social issues. Pretoria: Van Schaik Publishers.

BEZUIDENHOUT, C. \& SPIES, G. (eds) 2006. Sexual abuse: dynamics, assessment and healing $\left(1^{\text {st }}\right.$ ed). Pretoria: Van Schaik Publishers.

BISSELL, M. 2000. Socio-economic outcomes of teen pregnancy and parenthood: a review of the literature. The Canadian Journal of Human Sexuality, 9(3):191-203.

BLACK, P., JEFFREYS, D. \& HARTLEY, E. 1993. Personal history of psychosocial trauma in the early life of social work and business students. Journal of Social Work Education, 29(2):171-180.

BLUNT, R. 2008. Turning apartheid around. In: GROSLING, G. \& HEAGNEY, L. (eds) Improving student retention in higher education: the role of teaching and learning. London: Routledge, Taylor and Francis Group.

BONG, M. \& SKAALVIK, E. 2003. Academic self-concept and self-efficacy: how different are they really? Educational Psychology Review, 15(1):1-15.

BRANDON, M., SCHOFIELD, G. \& TRINDER, L. 1998. Social work with children. New York: Palgrave.

BROOKS-GUNN, J. \& DUNCAN, G. 1997. The effects of poverty on children. The future of children. Children and Poverty, 7(2):55-77.

BROWN, D., ANDA, R., FELITTI, V., EDWARDS, V., MALARCHER, A., CROFT, J. \& GILES, W. 2010. Adverse childhood experiences are associated with the risk of lung cancer: a prospective cohort study. BMC Public Health, 10(20). [Online] Available: www.bio-medcentral.com/1471-2458/10/20. [Accessed: 01/10/2010].

BURTON, D., FOY, D., BWANAUSI, C., JOHNSON, J. \& MOORE, L. 1994. The relationship between traumatic exposure, family dysfunction, and post-traumatic stress symptoms in male juvenile offenders. Journal of Traumatic Stress, 7(1):83-93.

COLLINS, K. \& VAN BREDA, A. 2010. Academic support for first-year social work students in South Africa. Social Work/Maatskaplike Werk, 46(1):14-25. 
COOMBES, K. \& ANDERSON, R. 2002. The impact of family of origin on social workers from alcoholic families. Clinical Social Work Journal, 28(3):281-301.

CRESWELL, J. 2007. Qualitative inquiry and research design: choosing among five approaches ( $2^{\text {nd }}$ ed). California: Sage Publications.

CRESWELL, J. 2009. Research design: qualitative, quantitative, and mixed method approaches $\left(3^{\text {rd }}\right.$ ed). California: Sage Publications.

DOWling, E., GESTSDOTTIR, S., ANDERSON, P., VON EYE, A., ALMERIGI, J. \& LERNER, R. 2004. Structural relations among spirituality, religiosity, and thriving in adolescence. Applied Developmental Science, 8(1):7-16.

DUNCAN, G., YEUNG, W., BROOKS-GUNN, J. \& SMITH, R. 1998. How much does childhood poverty affect the life chances of children? American Sociological Review, 63:406423.

DYKES, G. 2009. Recognition of Prior Learning (RPL) and support: are the learning needs of RPL first-year students different? Social Work/Maatskaplike Werk, 45(3):314-326.

DYKES, G. 2010. Addiction. In: NICHOLAS, L.; RAUTENBACH, J. \& MAISTRY, M. (eds) Introduction to social work. Cape Town: Juta \& Co.

EARLE, N. 2008. Social work in social change: the profession and education of social workers in South Africa. Cape Town: HSRC.

EGELAND, B., CARLSON, E. \& SROUFE, L. 1993. Resilience as process. Development and Psychopathology, 5(4):517-528.

FERGUS, S. \& ZIMMERMAN, M. 2005. Adolescent resilience: a framework for understanding healthy development in the face of risk. Annual Review of Public Health, 26:399-419.

FERGUSSON, D. \& LYNSKEY, M. 1995. Suicide attempts and suicidal ideation in a birth cohort of 16-year-old New Zealanders. Journal of American Academy of Child \& Adolescent Psychiatry, 34(10):1308-1317.

FOCUS ADOLESCENT SERVICES. 2008. Your teen's friends - peer influence and peer relationships. [Online] Available: www.focusas.com/PeerInfluence.html [Accessed: 23/04/ 2008].

GIBBONS, J., BORE, M., MUNRO, D. \& POWIS, D. 2007. Using personal quality assessment for selection of social work students. Australian Social Work, 60(2):210-221.

GREYLING, W. \& BROKENSHA, S. 2006. Reflecting on the who-am-I? Essay as an integrative learning experience for adult learning. Journal for Language Teaching, 40(1):117132.

GROENEWALD, T. 2004. A phenomenological research design illustrated. International Journal of Qualitative Methods, 3(1). [Online] Available: www.ualberta.ca/ iiqm/backissues 13 1/pdf/groenewald/pdf. [Accessed: 26/11/2010].

HERBERT, M. \& HARPER-DORTON, K. 2002. Working with children, adolescents, and their families. United Kingdom: British Psychological Society and Blackwell Publishing Ltd.

HEPWORTH, D., ROONEY, R. \& LARSEN, J. 2002. Direct social work practice: theory and practice. California: Brooks/Cole. 
HIGGINS, D. \& McCABE, M. 2003. Maltreatment and family dysfunction in childhood and the subsequent adjustment of children and adults. Journal of Family Violence, 18(2):107-120.

JEKIELEK, S. 1998. Parental conflict, marital disruption and children's emotional well-being. Social Forces, 76(3):905-935.

KIRST-ASHMAN, K. \& HULL, G. 2002. Understanding generalist practice ( $3^{\text {rd }}$ ed). California: Brooks/Cole.

KRIESBERG, L. 2003. 'Us' versus 'them'. [Online] Available: www.beyondintractability. org/essay/identityissues/. [Accessed: 21/05/2009].

LAFRANCE, J., GRAY, E. \& HERBERT, M. 2004. Gate-keeping for professional social work practice. Social Work Education, 23(3):325-340.

LINLEY, P. 2003. Positive adaptation to trauma: wisdom as both process and outcome. Journal of Traumatic Stress, 16(6):601-610.

LUTHAR, S., CICCHETTI, D. \& BECKER, B. 2000. The construct of resilience: a critical evaluation and guidelines for future work. Child Development, 71(3):543-562.

MARKS, N., HEYJUNG, J. \& JLEUN, S. 2007. Death of parents and adult psychological and physical well-being: a prospective U.S. national study. Journal of Family Issues, 28(12):16111628.

MASTEN, A., BEST, K. \& GARMEZY, N. 1990. Resilience and development: contributions from the study of children who overcome adversity. Development and Psychopathology, 2:425444.

MOHAUPT, S. 2008. Review article: resilience and social exclusion. Social Policy \& Society, 8(1):63-71.

MUNRO, D., BORE, M. \& POWIS, D. 2005. Personality factors in professional ethical behavior: studies of empathy and narcissism. Australian Journal of Psychology, 57(1):49-60.

MYERS, H. \& TAYLOR, S. 1998. Family contributions to risk and resilience in African American children. Journal of Comparative Family Studies, 29(1):215-229.

NESS, C. 2009. The adverse childhood experiences (ACE) study. Schuyler Centre for analysis and advocacy (New York): Research briefing.

OLSON, C. 2006. Influence of early-life psychosocial trauma, family adversity, and selected other variable in the career choice of social workers. [Online] Available: Www.uky.edu/SocialWork/news/abstract dissertation.pdf. [Accessed: 18/06/2009].

RAMSDEN, P. 1992. Learning to teach in higher education. London: Routledge.

ROTHERAM-BORUS, M., STEIN, J. \& LIN, Y. 2001. Impact of parent death and an intervention on the adjustment of adolescents whose parents have HIV/AIDS. Journal of Consulting and Clinical Psychology, 65(5):763-773.

RUTTER, M. 1999. Resilience concepts and findings: implications for family therapy. Journal of Family Therapy, 21(2):119-144.

RYAN, M., McCORMACK, J. \& CLEAK, H. 2006. Student performance in field education placements: the findings of a 6-year Australian study of admissions data. Journal of Social Work Education, 42(1):67-84. 
SCHENCK, R. 2009. The socio-economic realities of the social work students of the University of South Africa. Social Work/Maatskaplike Werk, 45(3):299-313.

SCHILliNG, E., ASELINE, R. (Jr) \& GORE, S. 2007. Adverse childhood experiences and mental health in young adults: a longitudinal survey. BMC Public Health, 7(1). [Online] Available: www.biomedcentral.com/1471-2458/7/30. [Accessed: 01/10/2010].

SMOKOWSKI, P., REYNOLDS, A. \& BEZRUCZKO, N. 1999. Resilience and protection factors in adolescence: an autobiographical perspective from disadvantages youth. Journal of School Psychology, 37(4):425-448.

TSHIWULLA, L. 2007. Resilience in a Higher Education Institution. Inaugural lecture. University of the Western Cape, South Africa.

VAN BREDA, A. 2001. Resilience theory: a literature review. [Online] Available: WwW.vanbreda.org/adrian /resilience/resilience2.pdf. [Accessed: 18/06/2009].

VAN HARMELEN, U. 1999. Where has all the geography gone: a social constructivist perspective of curriculum 2005. South African Geographical Journal, 81(2):80-85.

WILBURN, V. \& SMITH, D. 2005. Stress, self-esteem, and suicidal ideation in late adolescents. Adolescence, 40(157):33-44.

Ethical clearance for the research was obtained from the institution where the study was undertaken.

Ms Glynnis Dykes, Department of Social Work, University of the Western Cape, Bellville, South Africa. 